\title{
O método compreensivo na obra de Dilthey
}

\author{
The comprehensive method in Dilthey's work
}

SIMEAO DONIZETI SASS ${ }^{a}$

\section{Resumo}

A hipótese do presente estudo é a seguinte: a obra de Dilthey representa a verdadeira fundamentação da metodologia própria ao estudo das ciências humanas. Em particular, a constituição de uma antropologia radicada no método compreensivo. Esse método é a principal estrutura sobre a qual podem ser erigidas as ciências humanas. Não se pretende vincular estreitamente toda a história do pensamento contemporâneo aos pressupostos da filosofia de Dilthey. A intenção é tecer um fio condutor suficientemente resistente a ponto de tornar-se a fundamentação da filosofia que se quer metodologicamente independente das ciências naturais.

Palavras-chave: Compreensão. Vida. Método. História.

\begin{abstract}
The hypothesis present in the given study is the following: Dilthey's work represents the true substantiation of the methodology proper to the study of human sciences. In particular, the construction of anthropology ingrained in the comprehensive method. This method is the main structure upon which human sciences can be edified, although we do not intend to closely relate all history of contemporary thought to Dilthey's philosophical suppositions. The main goal is to weave a common thread strong enough to become the grounding of a philosophy that aims to be methodologically independent of the natural sciences.
\end{abstract}

Keywords: Comprehension. Life. Method. History.

\footnotetext{
a Universidade Federal de Minas Gerais (UFMG), Belo Horizonte, MG, Brasil. Doutor em Filosofia, e-mail: simeao78@gmail.com
} 
"então pode-se apostar que o homem se desvaneceria, como à beira do mar um rosto de areia"

Foucault

\section{Introdução}

O presente ensaio constitui, ao mesmo tempo, o término e o início de meu trabalho de pesquisa. Desde 2006, em meu estágio de pós-doutorado, investigo a questão das emoções na obra de Sartre. Tal pesquisa originou uma série de publicações e estudos sobre um tema muito importante, não só para os pesquisadores da obra de Sartre, mas para a discussão acerca da metodologia das ciências humanas e da antropologia, em particular. A tese central defendida desde esses primeiros estudos pressupõe a necessidade de elaboração de uma antropologia que fundamente a psicologia e a teoria das emoções. Não serão desenvolvidos todos os aspectos desta tese central. Será destacada somente a questão metodológica que surge desde as primeiras publicações de Sartre. O problema levantado circunscreve a relação entre a subjetividade e a objetividade na elaboração filosófica. Essa relação necessita de uma fundamentação filosófica satisfatória para a abordagem clara e inequívoca da especificidade metodológica do estudo dos temas elencados acima. Busca-se estabelecer a correlação entre a subjetividade e a objetividade de maneira equânime e equilibrada, sem recair no materialismo vulgar nem no idealismo subjetivo.

A tese que queremos anunciar no presente estudo é a seguinte: a obra de Dilthey representa a verdadeira fundamentação da metodologia própria ao estudo das ciências humanas. Em particular, a constituição de uma antropologia radicada no método compreensivo. Esse método é a principal estrutura sobre a qual podem ser erigidas as ciências humanas. Como é possível notar, não se pretende vincular estreitamente todos esses pensadores aos pressupostos da filosofia de Dilthey. A intenção é tecer um fio condutor suficientemente resistente a ponto de tornarse um tema agregador da filosofia contemporânea e um ponto de imantação da filosofia que se quer metodologicamente independente das ciências naturais.

Para tanto, desenvolveremos os seguintes tópicos: 1 - aspectos biográficos de Dilthey; 2 - esboço de definição do método compreensivo; 3 - compreensão e ciências do espírito; 4 - a humanidade das ciências humanas; 5 - compreensão e literatura e 6 - compreensão e biografia. Tais aspectos não têm como intenção principal esgotar o tema em questão, dado que a própria proposta de Dilthey apresenta-se de forma ensaística e dinâmica. O principal objetivo é identificar 
temas que foram abordados por um número significativo de filósofos e pensadores, explicitamente ou não seguidores do caminho iniciado por seu fundador. Se o pensamento de Dilthey, hoje, não ocupa um lugar de destaque nas academias e nos debates teóricos, é pertinente perguntar se o seu relativo esquecimento não é justificado pela opção metodológica predominante na filosofia e nas ciências humanas que abraçaram, por vezes, sem a devida crítica, a metodologia das ciências naturais. Como lembrou muito bem o professor Hans-Ulrich Lessing, no artigo "Wilhelm Dilthey - O filósofo das ciências humanas", no dossiê publicado pela revista Aoristo, o iniciador das ciências do espírito nunca foi tão atual.

Mobilizar as teses defendidas por Dilthey nos dias atuais significa também colocar em debate temas e problemas discutidos pela filosofia, pela psicologia, pela antropologia, pela ciência política, pela biologia e pelas ciências ligadas ao cérebro. É curioso notar que os debates contemporâneos relativos ao emprego de tecnologias computacionais, da matemática e da genética não são temas recentes ou novos. Ampliando o espectro da temática, como faz Dilthey em diversas ocasiões, as propostas dos pitagóricos, dos defensores do socratismo ou do platonismo, assim como os seus desdobramentos no estoicismo e epicurismo, constituem duas grandes linhas da filosofia ocidental. Se a matemática foi um referencial teórico e metodológico de primeira ordem desde o surgimento da civilização; a literatura, a metafísica, e a religião constituíram planos igualmente agregadores desse mesmo processo civilizatório. Não se trata de colocar uma orientação metodológica segura, indubitável, de um lado, e as especulações literárias e subjetivas de outro, como se fossem adversárias. A questão que Dilthey coloca situa-se no plano da teoria do conhecimento. Se desde o início da filosofia as barreiras entre essas duas grandes orientações metodológicas sempre foram alteradas e transpostas, a inovação da filosofia de Dilthey surge a partir da corajosa iniciativa de elaborar um método independente e distanciado igualmente da matemática, da biologia e da física. Isso não significa que essas ciências e suas metodologias correspondentes não sejam válidas ou não devam ser valorizadas em seus campos específicos. O que se coloca em questão é exatamente a viabilidade de transposição dessas ciências e de suas metodologias ao campo daquilo que foi denominado espírito. Áreas do saber como o direito, a literatura, a história, a economia, a religião, a arte e a filosofia devem ser estudadas exclusivamente a partir dos pressupostos da matemática e das ciências naturais? Não seria necessário e urgente a elaboração de um método específico para esse imenso campo da cultura denominada humanidade? Essa é a questão que Dilthey levanta em seu tempo e que ainda hoje reverbera em todos os campos do conhecimento humano. Essas questões serão abordadas, no limite deste estudo, a seguir. 


\section{Aspectos biográficos de Dilthey}

Wilhelm Dilthey nasceu em 19 de novembro de 1833, em Biebrich, na Alemanha e faleceu Seis am Schlern, atual Austria, em 1911. Lecionou na universidade da Basileia, estudou a óptica de Helmholtz e a psicofísica de Fechner. Prosseguiu suas pesquisas estudando psicologia, história e literatura. Posteriormente, lecionou nas universidades de Kiel e Bratislava e em 1882 ocupou a cátedra de Lotze na Universidade de Berlim. Em 1883, publicou o primeiro volume de sua Introdução às ciências humanas.

A contribuição original de sua obra está radicada na construção das chamadas ciências do espírito ou atualmente denominadas ciências humanas. Um dos pilares do construto proposto pelo filósofo estabelece a conexão indissociável entre as ciências do espírito e a vida. Não só no sentido de um tema abstrato ou de uma ideia geral, mas na perspectiva de uma experiência vivida por cada pessoa historicamente situada. A consequência imediata dessa proposta é a valorização da condição histórica da própria constituição dessas ciências. Tal tese implica a reavaliação de um conceito clássico das chamadas ciências formais ou das ciências naturais, que é a questão da verdade. Esta situa-se indiscutivelmente no plano evolutivo e mutável. A operação clássica das ciências naturais fundada na determinação dos pontos fixos inabaláveis do edifício científico não encontra na proposta de Dilthey a mesma configuração.

Esse é o primeiro aspecto que o diferencia das filosofias tradicionais, o tema fundamental proposto é a vida, em particular a vida humana historicamente construída. É esse o fato e o dado fundamental a partir do qual as ciências do espírito são elaboradas. O ser humano e o seu meio circundante encontram-se envoltos pela vida. Conhecer esse dado fundamental pressupõe deslindar as conexões psicofísicas e psicológicas não só de um ser humano, de uma pessoa, mas as conexões entre essas pessoas, ou seja, da relação entre indivíduo e a sociedade. A vida passa a ser não só um conceito abstrato e formal, mas o ponto de partida real e concreto de todo conhecimento. Tema que diz respeito ao ser humano e aos produtos de suas atividades objetivadas que constituem aquilo que se chama cultura.

Outro pressuposto fundamental e original intuído por Dilthey é a inseparabilidade entre os diversos aspectos da vida humana. A representação de uma atividade, o sentimento que o anima e a vontade que determina todos os atos humanos nunca são considerados separadamente. Em cada objetivação pessoal de uma elaboração interior que solicita exteriorização, a representação (ou o 
pensamento), o sentimento e a vontade perfazem uma totalidade que se diferencia pela acentuação de cada um desses aspectos, mas nunca sem os demais. Tal postulado, ainda não valorizado adequadamente pelo pensamento contemporâneo, pode ser o ponto de partida de uma série de investigações e pesquisas voltadas para a concepção totalizante da realidade humana, abordada em sua unidade e diversidade coetâneas. Tal viés englobante não encontra parâmetros nas metodologias fundamentadas tanto na matemática quanto nas ciências naturais. Nessas ciências prevalece a parcialidade, a divisibilidade, o isolamento de partes de um todo que nunca chegam a ser reunidas após o esquartejamento praticado pela filosofia da análise. Lembrando a perspectiva de Bergson, recusa-se a identificação entre a atividade do conhecimento e a produção de conceitos abstratos e desconectados da vida concreta. A tarefa das ciências humanas, para Dilthey, nunca será a de erigir conceitos universais abstratos e válidos indistintamente. Ela terá como base a perspectiva de formação do ser humano em seus aspectos morais e culturais. Tendo como fim a proposição de valores que elevem cada vez mais a condição humana ao patamar de realização plena de todas as suas potencialidades. O conhecimento obtido com as ciências do espírito nunca reduz o ser humano a um objeto, ele o promove ao status de verdadeiro sujeito da história.

Outro aspecto inegavelmente contemporâneo das reflexões elaboradas por Dilthey diz respeito ao papel que a filosofia deve exercer no sentido de criticar os conhecimentos elaborados pelas ciências naturais. É óbvio que não são relegadas essas ciências a um lugar menor ou isoladas do campo da cultura. Toda produção de conhecimento diz respeito ao mundo da cultura elaborado pelo homem. O papel crítico da ciência do espírito, contudo, exige a postura de não alinhamento incondicional aos pressupostos metodológicos das ciências naturais. Se a biologia e a genética hoje perfazem uma espécie de paradigma científico universal, adaptável e utilizável em todas as áreas das ciências, do conhecimento, da cultura, e do saber, tal panorama não era totalmente estranho ao nosso autor. Ele também conheceu o sucesso de teorias como o utilitarismo, a psicofísica, a biologia, o darwinismo social, o positivismo, ou seja, todas as propostas científicas consagradas a partir do século XIX. Ele não relega tais propostas ao campo da execração ou da inutilidade, elas são evoluções e desenvolvimentos inscritos no campo da evolução da própria cultura humana. Mas ele não se rende ao tentador processo de adesão incondicional ao pressuposto de que a matemática, os métodos científicos das ciências naturais e a busca de uma verdade universal abstrata sejam as alternativas exclusivas da atividade do pensar e do conhecer. É exatamente nesse contexto de uma espécie de "positivismo ampliado" que ele encontra espaço para a 
construção de uma metodologia específica para a compreensão da atividade humana, que se manifesta de modo geral na religião, na filosofia, nas artes, nas ciências sociais e políticas.

Retomar o estudo de Dilthey representa também resgatar a própria identidade da filosofia como ciência do espírito, reinterpretando igualmente o papel formador das reflexões sobre a religião, a arte, a literatura, a economia, isto é, as produções humanas que construíram a própria história universal. Repensar a utilidade do método compreensivo pode significar uma crítica válida e construtiva tanto para a filosofia quanto para ciências naturais. Esse resgate representa igualmente a chama viva de uma atividade reflexiva que não se rende ao processo de transformar um paradigma em solução universal de problemas tão díspares e plurais. Reler Dilthey, em nossos dias, é imperativo. Ele nos ensina que a cultura como produção última da vida, da história e da reflexão não existe na forma de uma tabela periódica. A cultura é criação e renovação criadora que possibilita ao próprio homem compreender-se como produtor e produto de suas ações historicamente situadas.

\section{Esboço de definição do método compreensivo}

A edificação das ciências do espírito iniciada por Dilthey encontra no método compreensivo um de seus aspectos basilares. A dificuldade de definir sistematicamente essa proposta é conhecida por todos aqueles que se voltam para o estudo do tema. Não temos a pretensão de elaborar uma definição categórica da compreensão. Faremos uso de obras do próprio autor e de alguns comentadores que se dispuseram a estudar profundamente o tema no intuito de explicitar de forma minimante satisfatória tal termo. Tentando circunscrever o que Dilthey expressa com a palavra compreensão, é possível identificar uma primeira ideia geradora nas páginas da obra publicada em 1900, denominada O nascimento da hermenêtica, traduzida por Alfred Keller e Maria Nazaré de Camargo Pacheco Amaral. Nessa obra da fase final de sua vida, Dilthey afirma:

\footnotetext{
A compreensão nesse sentido mais amplo, é o procedimento fundamental a ser aplicado a todas as demais operações das ciências do espírito [...] Assim como nas ciências da natureza, todo conhecimento das leis só é possível em razão de elementos passíveis de serem medidos e contados nas experiências e de regras nelas presentes. Da mesma maneira, nas ciências do espírito toda proposição abstrata só é justificável por sua relação com a vitalidade psíquica que é dada na vivência e na compreensão (DILTHEY, 2010, p. 381).
} 
Essa exposição sintética torna possível intuirmos, primeiramente, a distinção metodológica estabelecida entre as ciências naturais e as ciências do espírito. Fica evidente que a compreensão parte do princípio de que o conteúdo e o sentido das objetivações do espírito humano somente podem ser captados se os dois fatores estiverem contemplados nessa tarefa, quais sejam, a vivência e a perspectiva psicológica da pessoa que vive tal experiência. Essas duas condições básicas para a elaboração compreensiva revelam a ineficácia da metodologia das ciências naturais, dado que elas sempre visam elementos impessoais, universais e abstratos, que realmente podem ser identificados na matemática e nos objetos das referidas ciências. Toda produção do espírito humano, por outro lado, envolve a experiência histórica concreta de uma pessoa constituída de atividade reflexiva, sentimento e vontade. Tais características exigem um procedimento próprio. É exatamente a essa necessidade que a compreensão visa atender.

A compreensão encerra, como é possível notar, questões clássicas da teoria do conhecimento. Como é possível entender o que outra pessoa manifesta e como é possível expressar o que pensamos? Essa questão, discutida desde a antiguidade, refere-se ao problema da elaboração do conhecimento e de sua transmissão. É evidente que as metodologias positivas criam a sua própria linguagem, as suas próprias fórmulas, as mais universais e abstratas possíveis, para que sejam entendidas por qualquer civilização em qualquer tempo. Talvez, a matemática e seus símbolos sejam a expressão mais acabada das exigências de um conhecimento universal. Ocorre que nem todos os problemas podem ser resolvidos desta maneira. Quando nos confrontamos com um texto literário, com um escrito religioso, com a enunciação de leis e de regras, com uma obra de arte, uma teoria econômica ou tratado de metafísica, todas essas manifestações históricas e culturais da civilização humana devem ser entendidas de uma maneira precisa e, ao mesmo tempo, circunstanciada. A essas dificuldades todas acrescenta-se a individualidade do autor ou dos autores, as suas convicções pessoais, culturais, morais, o seu contexto histórico, social e antropológico. Em suma, a complexidade dessas manifestações culturais exige uma postura que supera, em muito, a capacidade que a matemática demonstra de configurar uma linguagem universal, cujo entendimento é evidente a todo ser racional.

Um símbolo matemático, uma fórmula elaborada pelo estudioso da física ou da química podem ser entendidos por qualquer ente racional que domine os conhecimentos necessários. $\mathrm{O}$ apelo ao caráter racional e lógico satisfaz as necessidades de diálogo entre aqueles que dominam os códigos elaborados pelas ciências exatas e naturais. É como se todos dominassem uma mesma 
linguagem. É possível admitir que a comunicação entre as pessoas que dominam tais conhecimentos seja evidente, isenta de incompreensões profundas. Quando se toma, entretanto, um texto religioso ou filosófico, seja de períodos antigos ou contemporâneos, a comunicação entre o autor e o leitor se faz de uma forma muito mais complexa. Conhecer a gramática, a língua de determinado texto é fundamental para a tarefa do entendimento, mas é sabido que o contexto é tão importante quanto o texto. Além disso, as motivações que levaram o autor ou os autores a expressarem-se objetivamente através de uma linguagem escrita formal, ou por meio de manifestações artísticas ou simbólicas, para Dilthey, são partes constitutivas da expressão objetiva. Exigese um trabalho muito mais complexo de interpretação, contextualização e decifração. Na verdade, tais escritos solicitam um verdadeiro diálogo entre o leitor e o autor. E se eles estão situados em momentos históricos distintos, esse diálogo se torna ainda mais complexo. Surge, então, um outro elemento da metodologia compreensiva que é a necessidade de uma pessoa compreender a outra, ou seja, estabelecer uma verdadeira comunicação. Nas palavras do filósofo:

A possibilidade de apreender o que o outro é, constitui um dos mais profundos problemas da teoria do conhecimento. Como é possível que o indivíduo transforme uma objetivação individual da vida do outro, oferecida pelos sentidos, em nível de entendimento objetivo universalmente válido? A condição da qual depende essa possibilidade está no fato de que não pode ocorrer nada numa objetivação individual da vida do outro que não esteja presente também na vitalidade daquele que compreende. As mesmas funções e os mesmos componentes estão presentes em todas as individualidades, sendo que as aptidões, nos diferentes seres humanos, se distinguem tão somente por seu grau de intensidade. É o mesmo mundo exterior que se reflete nas imagens de sua mente (Ibidem).

Dilthey demonstra sinteticamente nessa proposição que a compreensão envolve inúmeros fatores, todos eles ligados ao processo de comunicação, que, por sua vez, é a exteriorização de uma pessoa situada historicamente no mundo. Pessoa imbuída de perspectiva subjetiva e objetiva, com seus desejos e necessidades, que se lança no trabalho de manifestar-se aos outros. Esse indivíduo concreto não vive só. Ele está circundado pela sociedade. Em sentido amplo, a sua posição no mundo é o seu projeto. Outro aspecto importante a ser destacado é o fato de que se identifica em todas as pessoas as mesmas capacidades. Isso significa que a comunicação é sempre possível e, por conseguinte, a atitude compreensiva surge sempre como a possibilidade primeva de comunicação. Dilthey chega a afirmar, em outro momento, que o desafio da interpretação é uma pessoa compreender a outra de forma mais completa que essa mesma pessoa poderia fazer em relação a si. Não seria essa a tarefa do psicólogo, por exemplo? O desafio da atitude compreensiva é elucidar o sentido das manifestações concretas e pessoais de tal forma que tanto a pessoa 
que objetivou as suas intenções quanto aquela que interpretou essas subjetivações cheguem ao termo comum de estabelecer esse diálogo compreensivo. Não se propõe nenhuma espécie de obscurantismo subjetivo que visaria impedir a atividade racional de elucidação das manifestações, ao contrário, busca-se expressar a infinidade de aspectos das manifestações culturais humanas, demostrando a sua riqueza, a sua profundidade. Sem, no entanto, desconsiderar que esse trabalho é infinito. Nas ciências naturais e na matemática a intenção é limitar, delimitar, circunscrever com exatidão o objeto a ser explorado. A metodologia compreensiva caminha em sentido oposto, ela não quer revelar um só aspecto ou uma ideia abstrata manifestada nas objetivações culturais, ela quer explorar exatamente a diversidade e a multifacetada amplitude dos significados das ações e das manifestações humanas, daí a sua infinita tarefa de interpretação das manifestações culturais.

A exterioridade do mundo é o dado, é o fato indubitável a partir do qual todas as individualidades se manifestam. É o mundo real que garante objetividade a todo o existente e este mundo não é uma ideia abstrata, um conceito vazio, ele é o solo no qual toda humanidade germina e tudo existe. $\mathrm{O}$ mundo é o palco da existência. Fica evidente que o trabalho de compreensão não é uma elaboração romântica, idealista, subjetivista e irreal. A compreensão se dá a partir das vivências do mundo concreto partilhadas por todos os seres que o habitam. A expressão objetiva dessas vivências torna-se um livro que deve ser interpretado em suas multifacetadas perspectivas, mas essa interpretação não pode tomar como objeto uma invenção do intérprete sem o fato vivido coetâneo da experiência concreta.

\section{Compreensão e ciências do espírito}

Pelo exposto até aqui, fica evidente que a compreensão é a conduta metodológica básica das ciências do espírito. Mas esse método e esse procedimento estão radicados no ponto de partida que não é a priori ou abstrato, mas concreto e histórico. O fundamento das ciências do espírito é a vida, mais especificamente, a vivência humana, a experiência de estar situado historicamente no mundo concreto e agindo em função de intenções e fins em um meio social englobante. HansUlrich Lessing, sintetiza as ciências do espírito da seguinte forma: "Dilthey apresenta uma filosofia da vida histórico-hermenêutica, e aos conceitos de base da sua filosofia contam "vida", "vivenciar", "vivência”, “compreensão", "estrutura" e "contexto” (LESSING, 2019, p. 16). Em síntese, "A vida não é uma potência metafísica, mas o primeiro e último fato do filosofar mesmo" (LESSING, 2019, p. 16). 
A distinção entre as metodologias parte do pressuposto de que o mundo natural é mudo, carecendo de uma explicação que visa sempre determinar as suas características gerais. O mundo espiritual, em contrapartida, necessita ser compreendido de uma maneira distinta. Ele é o mundo humano, que envolve os sentidos das ações e que devem ser traduzidas de forma adequada. Nesse mundo imperam a liberdade e a historicidade. Se estamos em casa no mundo humano, o mundo natural sempre nos parece um tanto estranho. A estratégia teórica básica, nesse caso, visa estabelecer para esses objetos relações de causa e efeito. Essa fórmula não é a mais adequada porque limita o próprio significado daquilo que deve ser entendido, ou seja, os conceitos gerais, estabelecendo determinações causais a uma espécie de resultado obrigatório unificado.

Essa diferenciação teórica revela que as ciências do espírito têm como intenção e temas centrais o espírito humano, ou seja, a própria humanidade em sua criação histórica. Teremos oportunidade de discorrer um pouco mais sobre essa questão essencial não só para as ciências de espírito, mas para antropologia e também para a filosofia contemporânea. E a questão que antecipamos pode ser formulada da seguinte maneira: é possível considerar, ainda hoje, o homem como o centro das ciências humanas? Essa questão ganha relevo se pensamos nas propostas antropológicas, filosóficas e sociológicas que surgiram a partir da segunda metade do século XX.

Uma questão teórico-metodológica fundamental, na avaliação das duas orientações fundamentais, é o papel que o pesquisador-observador desempenha na construção do conhecimento. Será que é possível igualar a tarefa do biólogo, do matemático e do físico ao trabalho do filósofo, do sociólogo ou do artista? Retomando o tema da comunicação, como se dá a relação entre o objeto e o seu observador quando o tema é a natureza ou quando o tema é o trabalho de outro ser bumano? Se pensarmos no caso específico da pintura, se tomarmos como exemplo as obras do pintor Van Gogh, é possível desempenhar, neste caso, a atitude impessoal que o matemático adota frente aos seus cálculos? Essa questão é muito importante e revela a especificidade do conhecimento das produções humanas. Se é possível manter-se distante do objeto das ciências naturais, o envolvimento do pesquisador — com sua totalidade vivencial individual — não faria parte do próprio trabalho de interpretação da obra artística do referido pintor? Será que não é necessária a presença de um ser capaz de vivenciar experiências estéticas no trabalho de compreensão daquele que produziu essas obras? Não é necessário interpretar as vivências do pintor para compreender a sua obra? Não é necessário compreender como o pintor entendia a arte da pintura e como ele se situava nesse momento histórico para que sua exteriorização obtivesse seu real 
contorno? Por outro lado, qual o ganho que se opera com a suposta atitude imparcial, impessoal, técnica e objetivante na interpretação de uma obra de arte? É possível separar as vivências de Van Gogh, os seus dramas pessoais, os seus conflitos internos e sociais de suas pinturas? O literal valor, não só financeiro, de suas pinturas reside na totalidade pintor-obra? Van Gogh tinha consciência de que estava revolucionando a pintura? A leitura de suas cartas revela essa consciência? Usar suas cartas para compreender sua pintura é interferir na objetividade da interpretação de sua obra de arte? Considerar as pinturas como objetos em si, desvinculadas do contexto histórico, artístico e pessoal, significa realmente elaborar uma estética objetiva e científica? São essas questões que suscitam a necessidade inegável de retomar as teses elaboradas por Dilthey.

"A vivência e a compreensão constroem a base das ciências humanas, seu objeto é a esfera da expressão, o espírito objetivo, o espiritual expresso ou objetivado, i. e. o mundo espiritual" (LESSING, 2019, p. 23-24). Essa frase sintetiza não só o objeto e o método das ciências do espírito, mas a sua função, que é a de analisar a expressão objetiva das ações humanas. Alguns podem pensar que a compreensão é somente a tentativa de inspeção da interioridade do indivíduo, mas não é de forma alguma esse o objetivo. A universalidade conquistada pelas ciências do espírito pressupõe a objetivação das manifestações do espírito humano. É como se estivéssemos no plano de uma expressão objetiva fundamentalmente significativa, em todos os sentidos. A interpretação da vivência só pode ocorrer quando esta se objetiva na expressão concreta. É o espírito objetivado do ser humano que a compreensão visa decifrar. Só há compreensão por intermédio da expressão. E o sentido impresso na expressão surge da manifestação daquilo que foi vivenciado de algum modo. Interpreta-se, assim, sentidos e significados oriundos de experiências. Nesse âmbito, estamos bem longe dos paradigmas materialista ou idealista das teorias típicas do século XIX. Esse é outro aspecto decisivo. Dilthey cria, realmente inova, ao postular um novo modo de construir o conhecimento científico. Decisivamente, o positivismo é afastado. $\mathrm{Na}$ verdade, desmistificado em sua pretensa instauração dos referenciais inquestionáveis de todo saber e toda ciência.

Outra distinção importante em relação a essa espécie de positivismo difuso, criticado por Dilthey, é a consequente abordagem totalizadora que a compreensão opera, ou seja, a vida é sempre concebida em sua dimensão englobante toda vez que essa metodologia é empregada. A relação que determinada pessoa opera em vista do mundo exterior é, ao mesmo tempo, uma relação de vida, na relação existencial, constituindo o famoso círculo, não só hermenêutico, mas concreto, entre obra e produção. Desta forma, quando realizo algo, é minha realização que se 
objetiva, ela diz respeito aos meus valores, ao meu pensamento elaborado e aos meus sentimentos. A abordagem compreensiva ressalta e sustenta essa relação conectiva, essa conexão inegável entre o mundo, a vivência e ação.

É por essa razão que as diferenças metodológicas entre as ciências naturais e a humanas são claras.

Enquanto as ciências da natureza completam os fenômenos por meio de projeção de pensamento (Hinzugedachtes), as ciências humanas classificam, no que elas "traduzem de volta" a realidade exterior humano-históricosocial "à vivacidade espiritual da qual ela se originou". Nas ciências da natureza se recorre à fundamentos de explicação hipotéticos para a individuação, nas ciências humanas "as causas" da individuação são experimentadas "na vivacidade" (LESSING, 2019, p. 25).

Essa diferenciação revela a intenção de Dilthey de se desconectar do idealismo filosófico e científico. Ao invés de lançar mão de conceitos abstratos que teriam papel de ocupar as lacunas deixadas pelas explicações desconectadas entre si, a vida passa a ser a verdadeira conexão entre todos os fatos históricos e sociais. Ela é o fundamento de onde brotam todas essas conexões. A tarefa da compreensão passa a ser a de explicitar, interpretar e expressar essas conexões estabelecidas entre a vida e os seres viventes exteriorizadas em objetivações. Segundo Lessing (LESSING, 2019, p. 26), Dilthey afirma:

O compreender pressupõe uma vivência e a vivência se transforma em experiência de vida apenas no que o compreender guia para fora da estreiteza e da subjetividade da vivência à região do todo e do geral. E assim a compreensão demanda da personalidade individual para a sua completude o saber sistemático, tal como, por sua vez, o saber sistemático é dependente da apreensão vivencial da unidade de vida individual (apud DILTHEY, 1927, p. 143).

É essa circularidade entre a vivência, a expressão objetiva e a sistematização dessa expressão em saber que performa a compreensão. Tal circularidade estabelece uma dependência mútua entre as perspectivas. Essa dependência revela a totalidade que se faz inerente ao processo de compreensão. Tal configuração explicita outro tema muito importante para as ciências do espírito, a conexão entre a parte e o todo, entre o indivíduo e a sociedade. Um lado não pode ser pensado sem o outro. Um somente pode ser compreendido a partir do outro.

Explicita-se, desta maneira, a validade concreta da metodologia compreensiva. A atividade interpretativa desempenhada pelo espírito humano somente pode ocorrer a partir de exteriorização objetivada na história, isto é, somente aquilo que o espírito produz pode ser transformado em saber. Todas as impressões que o ser humano deixa na história e no mundo da cultura, todas as suas objetivações, passam a ser objeto da atividade compreensiva. É o que pode ser denominado de "espírito objetivo", que não significa a vitória da razão sobre a vivência, mas a busca 
pela compreensão através do retorno ao contexto no qual essa objetivação se fez, ou seja, à sociedade que tornou possível tanto a ação quanto a objetivação. O “indivíduo ator" surge no contexto da produção e da objetivação.

\section{A humanidade das ciências humanas}

Após a explicitação do sentido da metodologia compreensiva, é possível abordar alguns aspectos inerentes, tanto ao contexto da filosofia de Dilthey, quanto aos desdobramentos que as suas propostas significaram para a filosofia contemporânea. É possível afirmar que a questão crucial das ciências humanas é a sua "identidade" científica. É lugar comum avaliar que antropologia, a sociologia e a psicologia, sobretudo a partir do positivismo de Augusto Comte, passaram a reivindicar um espaço próprio no mundo do saber, esforçando-se cada vez mais para se distanciarem da filosofia e da metafísica. A própria distinção entre filosofia e ciência, tão propagandeada pelo positivismo, conduziu essas áreas do saber a uma busca incessante pela autoafirmação metodológica. Algumas mais, outras menos, conceberam exatamente a ideia de ciência como referencial introjetando nesse ideal as propostas de Augusto Comte. É interessante notar que os dois termos utilizados para classificar esses novos campos do saber passaram a conviver numa relação conflituosa. A ciência passou a considerar a bumanidade um objeto cada vez mais inconveniente aos seus ideais de universalidade e indubitabilidade. Influenciadas pelas metodologias das ciências naturais e pela matemática, as ciências humanas passaram a reforçar cada vez mais a necessidade de instauração de um procedimento absolutamente impessoal. A relação estabelecida entre o cientista e o seu objeto de pesquisa teve de passar necessariamente pela abstenção de qualquer juízo de valor. O cientista passou a ser uma espécie de veiculador da verdade existente e, o objeto, o foco de uma revelação. O cientista passou a ser a boneco do ventríloquo. Sendo o próprio ventríloquo a natureza e a lógica; e o discurso científico, por sua vez, as frases proferidas pelo boneco. Nesse sistema, a objetividade é a palavra de ordem, contrastando com a outra palavra fundamental que é a subjetividade. Esta última passou a ser cada vez mais exorcizada dos discursos das ciências incipientes. Se considerarmos a França dos anos 50 do século XX, por exemplo, o projeto das ciências humanas e sociais passou a representar o ideal positivista em sua forma difusa, mas, ao mesmo tempo, inegável. Quando pensamos em autores como Althusser, LeviStrauss e Foucault, e, de modo geral, os estruturalistas e pós-estruturalistas, é tentador compreender os respectivos projetos de fundamentação das ciências humanas e sociais a partir da inspiração positivista. Sobretudo exatamente quando se pensa no papel da subjetividade constitutiva 
desses saberes. A pergunta que podemos levantar é: o outro termo da expressão ciências humanas, ou seja, o humano, continuou a fazer parte desse projeto científico? Permaneceu o objeto homem parte dessas ciências? Em resumo, como foi concebida a humanidade no projeto das ciências humanas a partir da segunda metade do século XX na França? Para tomarmos somente um exemplo.

Essa digressão serve para ressaltar o acerto e a originalidade da proposta de Dilthey ao elaborar a fundamentação das ciências humanas. Vislumbrar uma metodologia própria aos saberes produzidos pelo homem, dentre outros objetivos, visa, sobretudo, tentar captar a produção humana a partir de uma atividade compreensiva que somente pode ser também humana. Ou seja, o homem produz e sabe que o faz, assim como conhece a intenção de seu ato. Sem adentrarmos na questão da inconsciência da vida e de seus representantes. Tema também abordado pelo autor em tela. Isso não significa que a abordagem objetivante pressuponha que a natureza somente possa ser conhecida pela própria natureza. Essa é uma questão de teoria do conhecimento interessante. Quando Dilthey diz que a natureza é muda, isso significa que ela não é capaz de elaborar uma reflexão sobre si mesma, ou seja, a natureza é objeto de conhecimento, ela não se faz conhecimento. Ela surge como objeto e não como o sujeito do ato de conhecer. O conhecimento da natureza pressupõe a atividade investigativa do ser humano. Não vamos entrar na discussão em relação aos animais vivendo em seu habitat. Não temos condições de divagar a respeito da existência ou não de transmissão de conhecimento entre os animais acerca da relação que eles estabelecem com a natureza. Que existe transmissão de conhecimento e de experiências entre a cria e o animal adulto, isso é um fato evidente. Mas fica a dúvida se isso pode ser caracterizado como conhecimento no sentido que o ser humano o toma em sua essência. Deixando essa reflexão de lado, é possível afirmar que a transmissão do conhecimento obtido na relação que o homem estabelece com a natureza recebe da linguagem uma concretização inegável.

A questão que surge a partir da proposta circunscrita até aqui é exatamente o papel do ser humano na produção do conhecimento das ciências humanas. Essa questão revela a necessidade de discutir-se o tema da reflexão. Se é possível admitir, e isso Dilthey o faz sem qualquer constrangimento, que as relações que cada ser humano estabelece com o seu meio circundante nem sempre são acompanhadas de reflexão correspondente, isso não significa que ele abole a existência da dimensão inconsciente no plano da vida concreta, nem que a reflexão é dissolvida nesse mesmo inconsciente. Dilthey evidencia as distinções e os níveis crescentes de complexidade das 
atividades humanas. Para aqueles que defendem a tese de que não há uma diferença fundamental entre o ser humano e os animais, dado que a razão e a própria reflexão não fazem parte da essência do humano, Dilthey responde no sentido de reforçar e ressaltar a necessidade de conceber o mundo humano a partir de uma complexidade de grau infinitamente mais elevado que as sociedades animais. Todos os aspectos que podem ser comparados entre os animais e o ser humano, no caso deste último, o grau de complexidade de elaboração realmente supera qualquer exemplo ou dado extraído da vida selvagem. Portanto, estabelecer uma analogia imediata entre a biologia e as ciências humanas, transformando, por exemplo, a ecologia no equivalente do modo de viver em sociedade, para nosso autor, é uma aproximação indevida e injustificável, sobretudo porque desconsidera exatamente aquilo que deve ser o foco central, qual seja, a especificidade de cada modo de vida e de suas manifestações no mundo. Se, no plano das matemáticas e das ciências naturais o trabalho é sempre o de desprezar as diferenças insignificantes — os famosos exemplos que não podem ser quantificados ou tabulados — buscando universalidades cada vez mais uniformes; o trabalho das ciências humanas deve ser exatamente o contrário, de buscar as diferenças, as especificidades, as concretudes e as formas de vida próprias. É nesse sentido que a reflexão ganha um papel importante, ela é a maneira pela qual se distinguem os sentidos, os valores e os fins.

As ciências humanas concebidas por Dilthey colocam a atividade humana no plano de uma constante tomada de consciência de sua história, de sua concretude e de sua mundanidade. Quando identifico em minha produção a inscrição de meus valores e de meus fins e quando o intérprete reconhece essa mesma subjetividade, manifesta-se de forma plena a comunicação que se estabelece entre esses sujeitos. Tal comunicação é a tomada de consciência no sentido amplo, intersubjetivo. Para objetivar suas vivências cada indivíduo precisa tomar consciência do que elas realmente são para si e para os outros. Para compreender tais vivências é necessário a outro ser humano operar a mesma conduta. Assim, o homem permanece no centro das ciências humanas, e a tarefa dessas ciências passa a ser exatamente a de revelar ao homem a sua humanidade, ou seja, o seu modo de viver no mundo.

Diante dessa constatação, quando retomamos os fundamentos dos autores mencionados como os mais importantes da segunda metade do século XX francês, podemos colocar em discussão se ainda podem ser denominados de cientistas sociais, filósofos ou antropólogos. É certo que alguns deles recusaram expressamente o título de filósofos. Não estariam eles mais próximos da atividade dos cientistas tradicionais, ou seja, daqueles que buscam construir uma ciência a partir de hipóteses e conceitos abstratos, de conceitos a priori, para depois sair à cata de exemplos 
que confirmem suas teses? Não seriam a gramática, a retórica e a fonética as "ferramentas" dessas novas metodologias? Não seria o homem, nessas ciências, somente o produto, sem ser o produtor? O ser falado sem ser o falante? Tais questões ressoam na reflexão contemporânea.

Em relação aos três pensadores franceses que citamos, o documento, a escrita, o texto são ferramentas fundamentais de suas elucubrações teóricas. O texto passa a ser objeto do cientista social e do antropólogo. Diferentemente das teses defendidas por Dilthey, o texto escrito passa a ser um objeto autônomo. Apregoam-se teses como: a "escrita sem autor", a "autonomia do texto e da obra", do "texto fora do contexto", da impossibilidade teórica de se estabelecer uma relação necessária entre obra e autoria. Enaltecem as pinturas sem assinaturas, os escritos sem dono. Nunca se falou tanto em literatura e nunca se falou tão pouco do escritor. Vejamos como Dilthey aborda esse tema tão caro ao pensamento contemporâneo.

\section{Compreensão e literatura}

Exemplificamos esse fato na maneira pela qual o poeta exprime sua vivência. Partindo de uma certa situação, ele faz que as pessoas e as coisas sejam vistas numa relação de vida com um eu ideal no qual está intensificada na fantasia sua própria existência e, dentro dela, o transcurso de sua vivência. É esta relação de vida que determina o que o verdadeiro poeta vê e exprime a respeito dos homens, das coisas e de si mesmo [...] Quando o historiador fala de situações e pessoas, saberá criar uma impressão de vida real tanto mais intensa quanto mais elementos dessas relações de vida ele fizer entrever [...] ele precisa dar às personagens, às coisas e aos acontecimentos aquela forma e cor em que eles mesmos criaram percepções e lembranças na vida pelo ponto de vista da relação de vida" (DILTHEY, 2010, p. 186-187).

Essas palavras de Dilthey expressam de maneira clara e objetiva a relação interativa, a conexão indissolúvel, o círculo hermenêutico estabelecido entre a vida, o escritor e o objeto de sua escrita. Destaca-se ainda que a árdua tarefa de relatar acontecimentos e fatos produzidos por outras pessoas tenta captar a “forma e a cor” impressas pela expressão original. Fica evidente que o material da produção poética é sempre a vida, em todas as suas perspectivas, sejam elas reais, imaginárias, fantasiosas ou projetivas. Em suma, em uma determinada situação, podendo ser acrescentada a palavra histórica, a compreensão capta as "relaçôes de vida" exteriorizadas em objetivações culturais. A própria questão da criação, seja artística ou histórica, pressupõe a vinculação estreita entre as situações concretas e a elaboração textual ou simbólica dessas vivências. É possível afirmar que somente partindo de uma realidade viva e real é possível elaborar fantasias e mundos excepcionais.

Tais ideias demonstram o caráter inequivocamente oposto ao modo como os referidos pensadores franceses do século XX abordaram as relações entre a literatura, a vida e a autoria. 
Fica sempre a dúvida em relação as reais intenções dessa "revolução científica" operada, sobretudo, a partir da consolidação do estruturalismo como a principal filosofia e método na França. Outra questão é a possibilidade de se conceber, no caso desses autores franceses, toda uma teoria da criação literária, da própria elaboração filosófica e da teorização das ciências humanas, relegando o papel do autor e do próprio escritor a um plano evidentemente secundário; cindindo de forma radical o círculo hermenêutico. Os escritos de Marx, os mitos das sociedades primitivas e os arquivos das bibliotecas de Paris, sempre foram tomados como os pontos de partida dos referenciais objetivos. Os elementos materiais desse estruturalismo ampliado, denominado aqui de "positivismo difuso", que permaneceu durante quase meio século, sempre foram identificados como textos. Fica sempre a interrogação a respeito da possibilidade de se elaborar uma teoria tão centrada no texto e, ao mesmo tempo, tão refratária à perspectiva da produção autoral desse mesmo texto. É como se o texto surgisse de si mesmo, como um ato mágico ou sagrado, da gramática, das regras da linguagem, dos artifícios retóricos e que o escritor fosse uma espécie de simples veiculador da ideia previamente existente no mundo. Parece que a estratégia metodológica de elaborar uma teoria fundada em ideias, em hipóteses tão semelhantes aos procedimentos matemáticos, ganhou corpo no século XX exatamente com a intenção de reconstruir e, ao mesmo tempo, desconstruir as ciências humanas e as ciências do espírito iniciadas a partir das reflexões de Dilthey. As ciências humanas passam a ser ciências sem tomarem o homem vivo e vivente como o foco de suas investigações. Uma vez mais, afirmamos que a leitura de Dilthey pode oferecer elementos para a reavaliação desta suposta filosofia crítica, ao refazer o percurso que o seu iniciador operou frente ao próprio kantismo, ao utilitarismo, ao positivismo e ao idealismo. Reler Dilthey hoje nos ensina a reencontrar a mesma estratégia dos cientistas do século XX tentando copiar as metodologias das ciências naturais e da matemática, para elaborar uma hipótese sem fundamento na realidade. Como um corpo sem alma, um discurso sem conteúdo, produzido a partir de ideias que não encontram nenhuma relação com a vida concreta e, mais do que isso, totalmente desconectadas da história real.

Para Dilthey, “o espírito só entende aquilo que ele mesmo criou. A natureza, que é objeto das ciências naturais, abrange a realidade produzida independentemente da ação do espírito. Mas tudo que recebeu a marca da ação humana constitui o objeto das ciências do espírito" (DILTHEY, 2010, p. 201). Fica evidente, a partir dessas palavras, o porquê as ciências do espírito são identificadas com as ciências humanas. Porque as duas expressões referem-se a uma mesma 
perspectiva originária. Elas remetem àquilo que foi elaborado, produzido e objetivado pela atividade humana. Essa produção envolve características próprias do ser que a criou. Nenhum ser está mais gabaritado para compreender essa produtividade que o próprio ser humano. Nenhum outro ser na natureza tem a capacidade de explicar ou compreender o que o homem criou. Somente ele tem a capacidade de compreender a si e aos outros. $\mathrm{Na}$ perspectiva abordada aqui, nenhum outro ser, terreno ou não, é capaz de operar o conhecimento adequado ao âmbito dessa ciência específica. Fica até muito estranho chamar o ser humano de objeto. Tal denominação é característica das ciências naturais porque não há evidentemente nenhuma identidade ontológica entre aquele que observa e o que é observado, a menos que os dois sejam reduzidos a simples organização molecular. No caso das ciências do espírito, a relação é exatamente oposta. O mesmo ser que produz é o ser que interpreta, não necessariamente a mesma pessoa; da mesma forma que o autor pode ser ou não aquele que interpreta a própria obra. Seja por uma relação consigo mesmo, seja por uma relação entre duas pessoas, as ciências humanas, ao menos na perspectiva aqui abordada, não podem abdicar da centralidade do ser humano nessa empreitada científica. Se as ciências humanas abandonam o referencial humano de sua atividade, elas perdem o seu sentido, ou melhor, passam a reproduzir um conhecimento inadequado àquilo que se quer conhecer.

Talvez, seja essa a grande questão teórico-metodológica que o pensamento contemporâneo deve reavaliar.

\section{Compreensão e biografia}

Dilthey publicou estudos sobre Hegel, Schleiermacher, Lessing, Goethe, Novalis, Hölderin e outros escritores. Uma característica original de todos os estudos integrantes de sua obra, em sentido amplo, sempre foi a de conectar aspectos biográficos, históricos, situacionais, políticos e culturais às concepções teóricas, filosóficas e metodológicas. Ele elaborou e publicou extensos estudos biográficos sobre Hegel, Schleiermacher e Goethe. Coerente com a sua proposta metodológica, a conexão entre autor e obra sempre foi enaltecida. Talvez, essa seja uma das características mais marcantes e, ao mesmo tempo, mais instigantes de toda a proposta de construção das ciências do espírito. A compreensão de uma obra, seja ela artística, filosófica, econômica ou legislativa, sobretudo aquelas publicadas por autores eminentes, para Dilthey, jamais pode desprezar o estudo biográfico do autor. Tal princípio metodológico mantém coerência com 
as teses anteriormente elencadas em nosso estudo que apontam a intrínseca conexão entre produção humana como manifestação individual e a objetivação social dessa mesma produção. Isso não significa que o conhecimento da vida e da história de um determinado autor seja suficiente para a compreensão da obra e das reflexões que ela originou. Mas, sem essa abordagem biográfica a própria compreensão do conteúdo da teoria ou da obra estética fica incompleta. Ao lembrarmos da interconexão entre representação, vontade e sentimento, e o caráter evidente de produção individual e autoral, mostra-se absolutamente necessária a reconstrução não só das ideias, mas das intenções, dos motivos e dos fins que o autor consagrou em sua objetivação das próprias vivências.

Dilthey afirma categoricamente que "as autobiografias constituem a expressão mais direta da reflexão sobre a vida" (DILTHEY, 2010, p. 243). Por essa razão, ele se lança no estudo de autores como Agostinho, Rousseau e Goethe. Tal projeto tem como intenção básica compreender como esses autores apreendiam e estabeleciam o nexo entre as várias partes de suas próprias vidas. Retomando a questão fundamental do significado dos momentos da vida, Dilthey estabelece que "ele é ao mesmo tempo valor vivenciado do momento e sua força produtiva" (Ibidem). Desse modo, fica evidente que a vida não é só o tema fundamental das expressões humanas, mas também a sua força, o seu impulso criador originário. Se é a autobiografia a expressão escrita da própria vida, ela encerra a essência da vida humana em sua objetivação histórica. Por outro lado, ela realiza o projeto das ciências humanas enquanto é, ao mesmo tempo, consciência do mundo e consciência de si objetivadas.

\begin{abstract}
A autobiografia é a forma mais instrutiva pela qual nos vemos confrontados com a compreensão da vida. Nela, o curso da vida é o fenômeno externo, aquilo que se manifesta aos sentidos. A partir dele, a compreensão avança para aquilo que produziu esse curso da vida dentro de um determinado ambiente. Como a poesia que compreende o curso da vida é a mesma que o criou, resulta uma intimidade especial da compreensão. O mesmo ser humano que procura o nexo na história de sua vida já formou um nexo de sua vida por diversos aspectos em tudo que sentiu como valores de sua vida, que alcançou seus fins, que esboçou como projeto de sua vida, que, ao olhar para trás, apreendeu como seu desenvolvimento ou, ao olhar para frente, como configuração de sua vida e seu bem supremo. É esse nexo que passa a ser formulado agora em palavras (DILTHEY, 2010, p. 245).
\end{abstract}

Essas belas palavras resumem de maneira categórica a importância da biografia e da autobiografia, não só para as ciências humanas, mas para a própria perspectiva compreensiva. Tal defesa enfática do valor da biografia para as humanidades, pode servir como ponto de partida para reflexões acerca do modo como as ciências humanas são elaboradas nos dias atuais. É fato que as livrarias estão abarrotadas de biografias de personalidades importantes ou até inexpressivas. Investigação relevante seria abordar a metodologia utilizada para a elaboração dessas obras. 
É fato que a história é a disciplina que mais ajuda na reprodução de tal estilo literário. No entanto, fica a pergunta em relação ao papel da filosofia e das demais ciências humanas nessa tarefa. Seria possível pensar em uma atividade laborativa interdisciplinar, uma verdadeira sinergia entre as ciências humanas, por exemplo, no trabalho de elaboração de escritos biográficos? Uma vez mais, relembramos os ensinamentos da metodologia estruturalista para interpelar a sua validade. Estaria Dilthey tão equivocado na valorização da biografia a ponto de colocar no centro das ciências humanas esse estudo indispensável? O leitor deve ter notado que nossa intenção foi estabelecer uma conexão necessária entre biografia, literatura e ciências humanas. Tais aspectos, ao menos na perspectiva que estudamos aqui, são absolutamente indissociáveis.

Relembrando a legendária frase de Foucault: "então pode-se apostar que o homem se desvaneceria, como à beira do mar um rosto de areia"; é possível perguntar se essa aposta teve um vencedor. Difícil resposta a ser elaborada, pois recaímos nas disputas entre as escolas, ironicamente, permeadas de interpretações acerca do que seja o homem. Enfim, a posição que podemos propor somente tem a oferecer a possibilidade de inserir no debate acerca da metodologia das ciências humanas contemporâneas a agonística, interpretada, agora, em chave compreensiva.

\section{Considerações finais}

Ao final das considerações sobre o tema da compreensão na obra de Dilthey, gostaria de acrescentar algumas palavras sobre a dimensão ética da proposta que expusemos sinteticamente ao longo do presente estudo. Tentamos evidenciar a inegável presença da humanidade nas ciências humanas. Estratégia que poderia soar absolutamente tautológica ou desnecessária se desconhecêssemos o curso que essas ciências percorreram ao longo do século XX. Diante das novas ciências que surgem como profetizadoras do futuro cibernético, poderíamos perguntar acerca do objeto das ciências do espírito. Reafirmando considerações anteriores, é preciso repensar a frase "objeto das ciências humanas". Tal expressão é adequada ao modo de operar das ciências naturais. As ciências humanas, iniciadas a partir das investigações acerca das ciências do espírito, segundo nosso autor, tem como foco principal a vida humana em sociedade historicamente situada.

A perspectiva ética que pode ser desenvolvida a partir dessa tese fundamental é a própria dimensão da formação do homem como ser histórico. O ser humano se faz homem elaborando 
e interpretando a sua história. As ciências humanas teriam como função básica explicitar ao homem a sua humanidade. Dilthey elenca quatro aspectos que poderiam ser derivados de sua proposta para as discussões acerca da ética.

O primeiro diz respeito ao fato de que a dimensão quantitativa do sentimento, ou seja, a quantidade de prazer que cada ser humano experimenta não pode ser fruída separadamente da vontade. Tal postulado insere, ao nosso ver, uma questão teórica contemporânea muito relevante: todo prazer tem um fim, tem um objeto determinado. Se isso é verdade, é preciso repensar as inúmeras formulações contemporâneas que situam o prazer no âmbito do inconsciente. É por essa razão que nosso autor pode afirmar: "é nisso que está a fruição ou o sentimento, de modo que cada todo vivenciado tem um valor não separado dele, desde que esteja presente na consciência" (DILTHEY, 2010, p. 523). O segundo aspecto afirma que o valor próprio das criações do espírito é um conceito histórico. O terceiro aspecto afirma que esse valor mantém uma relação interna com a receptividade histórica da maioria dos seres humanos e ocupa aí uma determinada posição. O último aspecto é elaborado da seguinte maneira: “assim, o reino da razão, de Hegel, é substituído pelo reino da humanidade e pela ordem das criações individuais dentro dele. Esses valores objetivos constituem, em sentido estrito, o patrimônio espiritual da humanidade, desde que incluam a possibilidade constante de experimentá-los (DILTHEY, 2010, p. 524).

Podemos ainda experimentar o patrimônio espiritual da humanidade? Essa é a questão e, ao mesmo tempo, a tarefa que Dilthey lega ao homem.

\section{Referências}

AMARAL. M. N, de C. P. "Dilthey: hermenêutica da vida e universalidade pedagógica". Transformação, Marilia, v. 35. n. 1, p. 89-114, 2012.

DILTHEY, W. Filosofia e educação: textos selecionados. Trad. Alfred Keller e Maria Nazaré de Camargo Pacheco Amaral. São Paulo: EDUSP, 2010.

DILTHEY, W. Ideias acerca de uma psicologia descritiva e analítica. Trad. Artur Morão. Covilhã: Lusosofia, 2008.

DILTHEY, W. Introducción a las ciencias del espiritu. Trad. Eugenio Imaz. México: Fondo de Cultura Económica, 2015. 
DILTHEY. W. Literatura y fantasía. Tradução de Emilio Uranga e Carlos Gerhard. México: Fondo de Cultura Económica, 2013.

DILTHEY, W. Vida y poesía. Trad. Wenceslao Roces. México: Fondo de Cultura Económica, 2016.

LESSING. H.-U. "Wilhelm Dilthey — O filósofo das ciências humanas". Aoristo. Toledo, v. 1, n. 3, p. 14-30, 2019. 